\title{
The Cause, Effect, and Possible Solution to Traffic Congestion on North Nicosia Roads, Cyprus: Experimental and Theoretical Approaches
}

\author{
Ahd Shawakha ${ }^{1 *}$, Hüseyin Gökçekuş ${ }^{1}$ and Youssef Kassem ${ }^{1,2}$ \\ 'Department of Civil Engineering, Near East University, 99138 Nicosia, Cyprus; \\ ahdgassanmohammed.shawakha@neu.edu.tr, huseyin.gokcekus@neu.edu.tr,yousseuf.kassem@neu.edu.tr \\ 2Department of Mechanical Engineering, Near East University, 99138 Nicosia, Cyprus
}

\begin{abstract}
Objectives: To analyze traffic congestion at North Nicosia intersections in Cyprus. Eight intersections in North Nicosia ware considered and analyzed using experimental and theoretical approaches. Methods/Statistical Analysis: Field data were collected and analyzed using SPSS software to find the most congested intersections in North Nicosia. Moreover, this paper presents a comparative analysis of the operational efficiency of intersections under a range of traffic conditions with different volume and turning ratios using SIDRA software. Average delay time, the degree of saturation, Level Of Service (LOS) and travel speed were used represent the operational efficiency of the intersections. Furthermore, SIDRA software produces many Measures Of Effectiveness (MOEs) of which four ( $\mathrm{HC}, \mathrm{CO}, \mathrm{NO}_{\mathrm{X}}$, and $\mathrm{CO}_{2}$ ) were chosen for analyzing the environmental impact of intersections. Findings: Based on the field data and SPSS results, it is found that Gönyeli, Göçmenköy, and Yenikent intersections are the most congested intersections in North Nicosia. Results of the current case demonstrated that the level of service for the intersections in North Nicosia is F with average delay and degree of saturation ranged from 10 to 51 second/veh and 0.42 to $1.03 \mathrm{veh} / \mathrm{c}$, respectively. It is concluded that North Nicosia intersections need further developments to reduce traffic issues. Based on SIDRA results, it is observed that LOS of the proposed intersections was B for Gönyeli, D for Göçmenköy and C for Yenikent intersections. In addition, statistical tests showed that the decrease in MOEs in all proposed intersections was statistically different from the emissions that occurred in the current cases. Application/Improvements: The proposed intersections could be used as a viable alternative to cut down vehicular emissions, making intersections more environmentally friendly and reducing the traffic issues.
\end{abstract}

Keywords: Level Of Service (LOS); Measures Of Effectiveness (MOEs), North Nicosia, SIDRA Software, SPSS Software, Traffic Congestion

\section{Introduction}

Traffic congestion is one of the numerous genuine worldwide issues for both developed and developing nations $s^{1-5}$. Traffic congestion is one of the most conspicuously worsening problems associated with traffic engineering and urban planning ${ }^{6}$, with clear implications on spheres of the urban environment ${ }^{\underline{7}}$ and lifestyle ${ }^{4,8}$. It has become a serious problem in many cities, especially in large cities 2 . Traffic congestion as a global phenomenon is predicted to get worse in the future ${ }^{9,10}$. Traffic congestion is one of the intolerable problems of urban area emerging due to a sudden increment in the private transport, affecting urban society, economy 11 .

North Nicosia, the Capital of Northern Cyprus, faces serious traffic problems. Too long, the urban transport policy has been characterized by a one-sided focus on the private car. The continuous increase of traffic problems has serious effects on the city's environment (air pollution, noise, etc.), road safety, and the quality of life and as a result, the city's attractiveness for business, shopping, and living is reduced.

*Author for correspondence 


\subsection{Study Problem}

Traffic congestion has a negative impact on street uses and daily exercises in North Nicosia. This negative impact has never been assessed, and the causes are not yet known. These days, traffic congestion is moving toward becoming a risk for the city's economic development by restricting the versatility of the street uses and increment deferral and fuel utilization. Thus, to reduce blockage, it is essential to evaluate the causes of congestion, the execution of the crossing point, measure the activity blockage and the level of administrations with a specific end goal of influencing the traffic to stream smooth and successful.

\subsection{Study Objectives}

This paper describes the Level of Service (LOS) and Measures Of Effectiveness (MOEs) of the current and proposed intersections in North Nicosia, Cyprus to reduce the traffic issues and cut down vehicular emissions. In the present study, the effect and causes of traffic congestion on the North Nicosia intersections were investigated. Two anonymous surveys were conducted to find the congested intersections in the studied area. Moreover, the goal of this paper is to find a simple possible solution to reduce the traffic congestions in North Nicosia.

\subsection{Study Significance}

The importance of the subject study is a result of the following issues:

1. It allows reaching a simplified strategy, which leads to assess the traffic issues in north Nicosia; and

2. It encourages the government to develop intelligent transportation system to reduce traffic jam.

\subsection{Study Limits}

The study limits are confined to the following:

\subsubsection{Spatial Limits}

400 questionnaires were distributed in North Nicosia randomly to different occupations such as Engineers, lawyers, Health scientist, Businessman/woman, students (especially who has a vehicle).

\subsubsection{Temporal Limits}

Studying starts by the beginning of February 2018 and it wraps up by end of May 2018.

\subsection{Study Terminology}

1. SPSS software: It is a tool to analyze the questionnaires data; and

2. SIDRA software: It is a tool to find the operational efficiency of current and proposed intersections.

\subsection{Study Equations}

This study seeks to assess the causes and effects of traffic congestion in North Nicosia and how it can be managed from the user's perspective. The subject study provides an answer to the following main questions:

Q1. Do you think there is traffic in North Nicosia?

Q2. What are the levels of the traffic congestion quantitatively for the chosen Intersections in North Nicosia? Andwhat are the causes of traffic congestion in the studied area?

Q3. What are the simplest possible solutions that can be applied to solve the traffic issues in North Nicosia?

Q4. Are there any statistically significant differences between the current intersections and the proposed intersections in North Nicosia?

Q5. What are the possible measures that are needed for the traffic congestion in the North Nicosia?

\section{Data Collection Procedure}

\subsection{Study Area}

North Nicosia is the capital city of Northern Part in Cyprus. Based on the field observation, it is found that Terminal, Merit Hotel, Göçmenköy, NEU, Dereboyu,

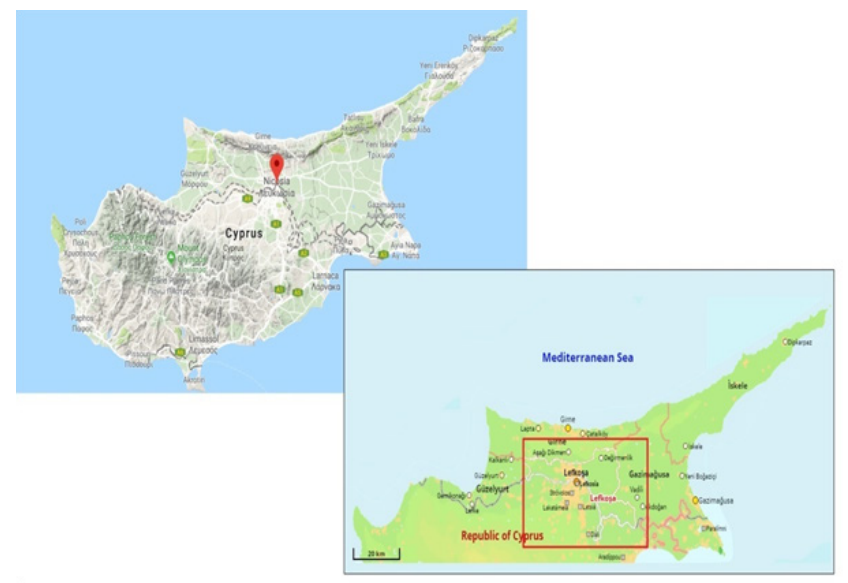

Figure 1. Depicts the location of the studied area. 
Gönyeli Roundabout, Girne Kapi and Yenikent intersections are the important congested intersections in North Nicosia.

Data were collected from filed and using a video camera with high storage capacity and long life battery. The data were recorded by a group of people distributed in the selected area. The time of recording started from off-peak $(7: 00 \mathrm{am})$ till another off-peak $(6: 00 \mathrm{pm})$ and is evaluated every 15 minutes. Furthermore, in order to find congested intersections in North Nicosia, questionnaires were made and distributed randomly according to the list of peoples by occupations like students (who have a vehicle), Engineers, lawyers, Health scientist, Businessman/ woman and so on.

\subsection{Data Analysis}

In this study, SPSS version 20 software and SIDRA computer program are used to analyze the data collected from the studied area.

SPSS is a software package for statistics used for interactive or batched statistical analysis. It is majorly used by survey companies, government, data miners, educational researchers, just to mention but a few.
SIDRA is a computer program, which commonly used in traffic engineering for analyzing the road of the selected area. It is used to estimate the operational efficiency such average delay, degree of saturation, LOS and so on of intersections and MOEs. A flowchart is given in Figure 2 to illustrate the analysis procedure of this study.

\subsection{Possible solution to Traffic Congestion in North Nicosia}

The researchers had been applied many solutions based on the previous study occurred in the world or Northern Cyprus. For an instant, Alsaid (2017) studied the traffic congestion in Famagusta, Northern Cyprus. In order to solve the traffic issue in Famagusta, the author applied one possible solution which is bridge and underpass. The author concluded that the preferred option was established to reflect the best transport operations in the studied area. In this study, the best possible solutions to traffic congestions are:

1. Additional lane (for Gönyeli intersection),

2. Adding bridge and underpass (for Gönyeli intersection),

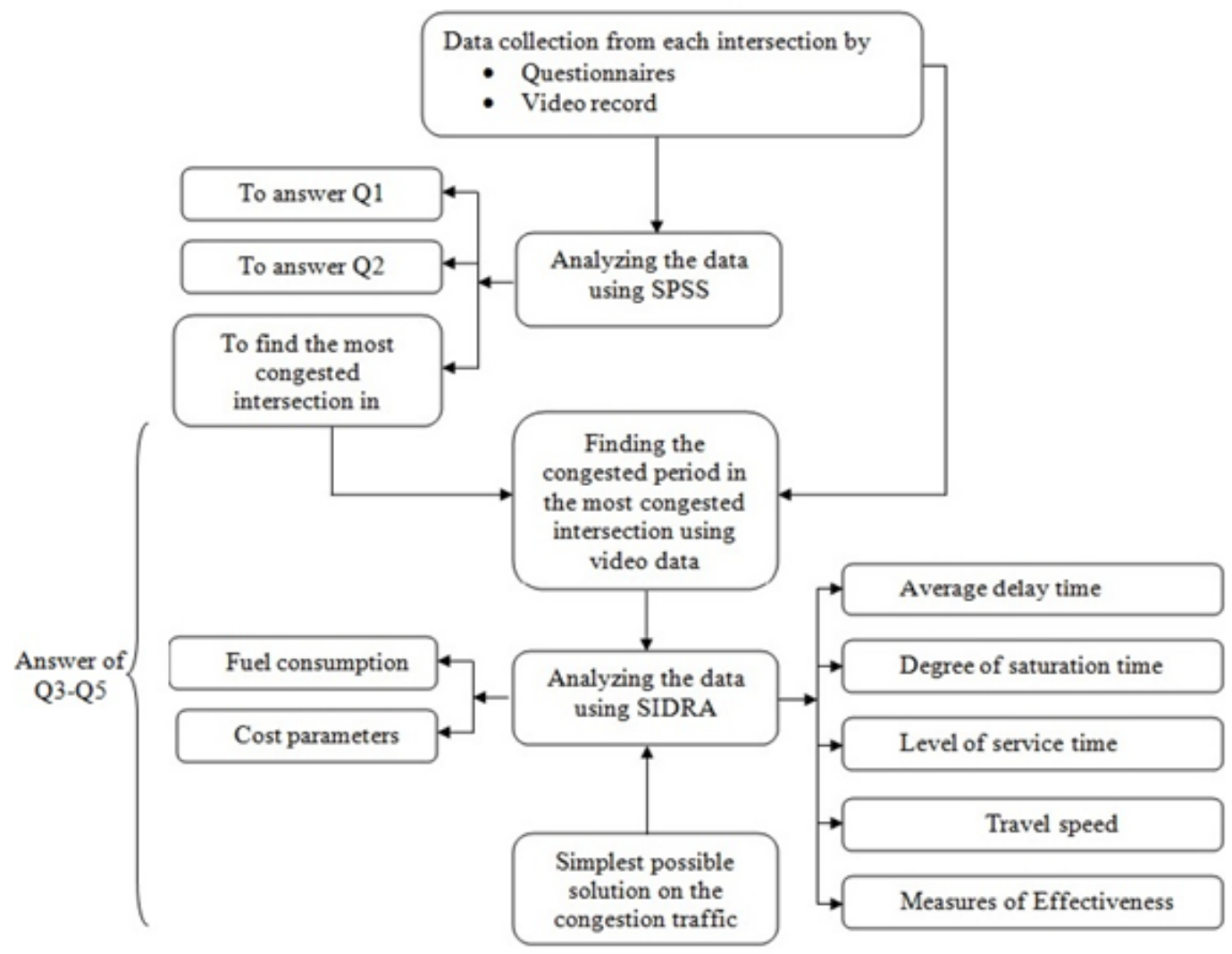

Figure 2. Flowchart of analysis procedure of the present study. 
3. Road expanding (from 3.1 to 3.5 for Yenikent and 3.1 to 4.0 for Göçmenköy intersections), and

4. Signals cancelation (for Yenikent and Göçmenköy intersections).

\section{Results and Discussions}

\subsection{SPSS Output}

In this study, 400 questionnaires are distributed randomly and 385 people responded. As shown in Table 1, the students have the higher response rate, which about $42.1 \%$ (162 respondents) followed by other occupations (26.9\%) and Engineers (18.7\%).

Table 1. Discriptive statistics for personal information

\begin{tabular}{|l|l|c|c|}
\hline Respondents & & Frequancy & Percentage \\
\hline \multirow{4}{*}{ Agender } & Female & 132 & 34.3 \\
\cline { 2 - 4 } & Male & 253 & 65.7 \\
\cline { 2 - 4 } & $18-20$ & 12 & 3.1 \\
\cline { 2 - 4 } & $20-30$ & 229 & 59.5 \\
\cline { 2 - 4 } & $30-40$ & 100 & 26 \\
\cline { 2 - 4 } & $40-50$ & 22 & 5.7 \\
\cline { 2 - 4 } & Above 50 & 22 & 5.5 \\
\hline \multirow{5}{*}{ Occupation } & Students & 162 & 41.2 \\
\cline { 2 - 4 } & Engineers & 72 & 18.7 \\
\cline { 2 - 4 } & Lawyers & 4 & 1 \\
\cline { 2 - 4 } & Health Scientist & 3 & 7.8 \\
\cline { 2 - 4 } & Business & 29 & 7.5 \\
\cline { 2 - 4 } & Others & 88 & 26.9 \\
\hline \multirow{5}{*}{ Total } & & $\mathbf{3 8 5}$ & $\mathbf{1 0 0}$ \\
\hline
\end{tabular}

As mentioned previously, the most important question in the questionnaire part in order to know if there is a real traffic issue in North Nicosia is

\subsubsection{Do you think there is Traffic in North}

\section{Nicosia?}

Figure 3 represents the frequency of the people who answered this question. It is noticed that 384 respondents answered Yes while 1 respondent answered NO. It can be concluded that North Nicosia has traffic issues.

After ensuring that there is a traffic issue in North Nicosia, Table 2 shows the level of traffic, causes of congestion, level of delay and the most congested intersection. In addition, the answer to the second question

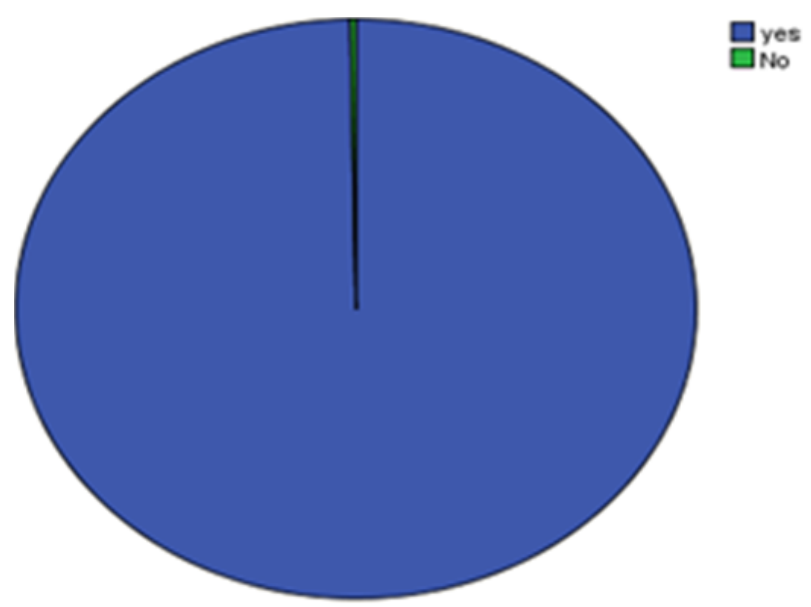

Figure 3. The answer of Q1.

in this study is shown in Table 2. It is observed that around $47 \%$ of respondents said that the level of traffic congestion in the studied area is high. Furthermore, it can be seen that the one of most effective in the traffic is poorly timed traffic signals followed by narrow roads in North Nicosia. According to Table 2, the most congested intersections in the selected area are Göçmenköyroundabout, Gönyeli roundabout, and Yenikent roundabout.

Table 2. Descriptive statistics of general information

\begin{tabular}{|l|c|c|}
\hline Level of Traffic & Frequency & Percentage \\
\hline Very High & 136 & 35.5 \\
\hline High & $\mathbf{1 8 4}$ & $\mathbf{4 7 . 3}$ \\
\hline Moderate & 57 & 14.8 \\
\hline Low & 8 & 2.1 \\
\hline Very Low & 0 & 0 \\
\hline Cause of Congestion & 196 & 25.5 \\
\hline Narrow roads & 216 & 28.1 \\
\hline Poorly timed traffic signals & 106 & 13.8 \\
\hline Work zone & 23 & 3 \\
\hline Vehicle breakdown & 63 & 8.2 \\
\hline Reduction in road capacity & 28 & 3.6 \\
\hline Special events & 81 & 10.4 \\
\hline Road construction activity & 2 & 0.2 \\
\hline Bad weather & 39 & 5.1 \\
\hline Traffic incident & 16 & 2.1 \\
\hline Others & 248 & 64.4 \\
\hline Level of Delay & \multicolumn{2}{|l}{} \\
\hline Daily & \multicolumn{2}{|l|}{} \\
\hline
\end{tabular}




\begin{tabular}{|l|c|c|}
\hline Level of Traffic & Frequency & Percentage \\
\hline Weekly & 89 & 23.3 \\
\hline Monthly & 36 & 9.4 \\
\hline Rarely & 9 & 2.3 \\
\hline Never & 2 & 0.5 \\
\hline Most Congested Intersection & \multicolumn{2}{|l|}{} \\
\hline Terminal Roundabout & 118 & 8.4 \\
\hline Merit Hotel Intersection & 158 & 11.3 \\
\hline Göçmenköy Roundabout & $\mathbf{2 4 2}$ & $\mathbf{1 7 . 2}$ \\
\hline NEU Intersection & 205 & 14.7 \\
\hline Dereboyu Roundabout & 186 & 13.3 \\
\hline Gönyeli Roundabout & $\mathbf{2 2 7}$ & $\mathbf{1 6 . 2}$ \\
\hline Girne Kapi Roundabout & 45 & 3.2 \\
\hline Yenikent Roundabout & $\mathbf{2 1 8}$ & $\mathbf{1 5 . 6}$ \\
\hline
\end{tabular}

\subsection{SIDRA Output}

Based on the results of SPSS software, the output results of SIDRA for the most congested intersections are discussed in this section. Figure 4 shows layout of the most three congested intersections in North Nicosia obtained by SIDRA computer program.

\subsubsection{Peak Period Volume of Roundabouts}

Based on video data, it noticed that the peak of the peak period for each selected intersections was 7:30-7:45 in the morning period and 4:30-4:45 in the evening period. At the peak period, the number of vehicles is calculated and the type of vehicles is obtained.

Moreover, it found that the highest number of vehicles of 1194vehicles occurred in the evening time at Göçmenköy roundabout. The data were collected for each line for all the directions (left, right and through) and assumed up during quarter an hour to recognize the number of vehicles passing each line. It is noticed that Dr. FazliKüçükBulvan (Fuar) phase has the highest number of vehicles passing it during the evening time. While the number of vehicles passing Şht. Mustafa Mehmet is about 144 vehicles, which can be considered as a minimum phase in Göçmenköy roundabout that the vehicles passing it in the same period.

Moreover, it observed that the highest number of vehicles of 1798vehicles occurred in the morning time at Gönyeli roundabout. Similarly, the data were collected for each line for all the directions It is found that Lefkoşa GüzelyurtAnayolu phase has the highest number vehicles passing it, which about 626 vehicles during the morning time.
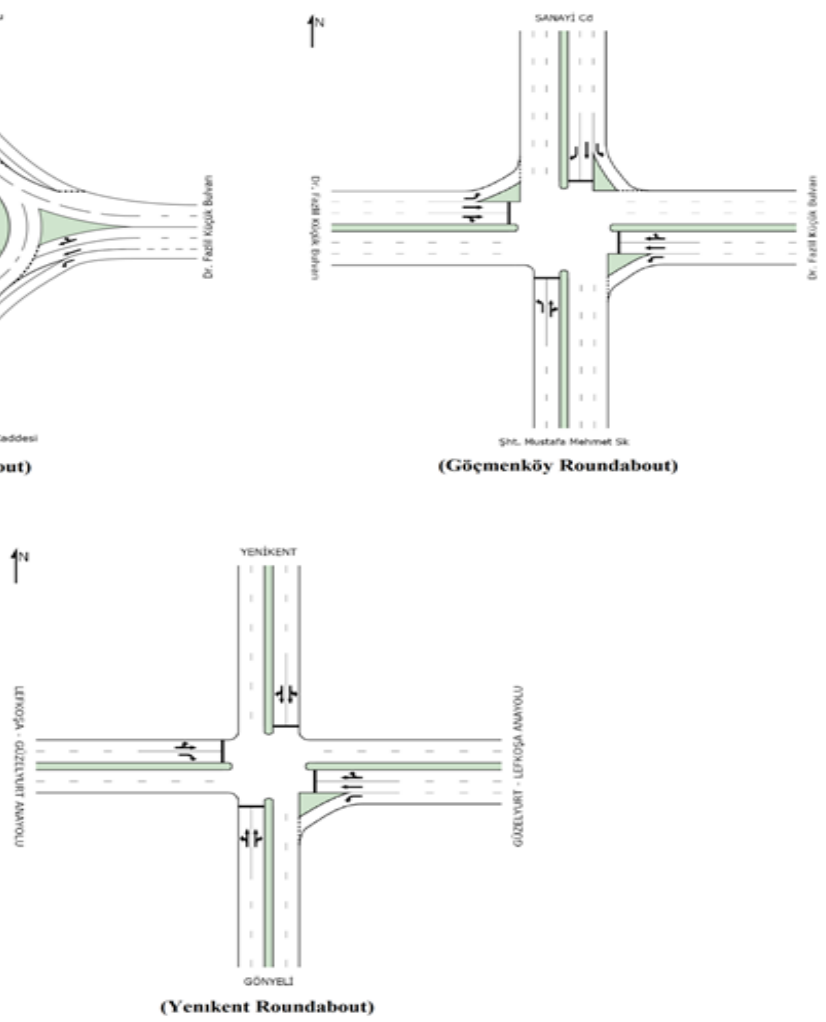

Figure 4. Layout of the most congested intersections in North Nicosia. 
Furthermore, it observed that during the morning time, the number of vehicles was the highest compared to the evening period, which was 883 and 879 vehicles, respectively.

It can be concluded that Gönyeli roundabout is the most congested intersection in North Nicosia based on the number of vehicles.

\subsubsection{Gönyeli Roundabout}

LOS is a method described the efficiency of traffic flow based on US Highway Capacity Manual (HCM). Results illustrated that Gönyeli intersection LOS in the current case is (F) as shown in Figure 5. After applying the first and second solutions, Gönyeli intersection LOS in the first and second case (first case: applying the first solution and second case: applying the second solution) are (F) and (B), respectively as shown in Figure 5 (b) and (c).

Moreover, Figure 5 shows that all phases in the second cases have two colors green and blue, green refers to LOS A and blue refers to LOS B, which has the minimum delay. Figure 6 is illustrated the relationship between average delay and phases of the intersection. It is observed that the average delay in all phases is nearly the same which is about 10 second/veh.

Results for travel speed is indicated in Figure 7, it was noted that all phases have a light and dark blue i.e.

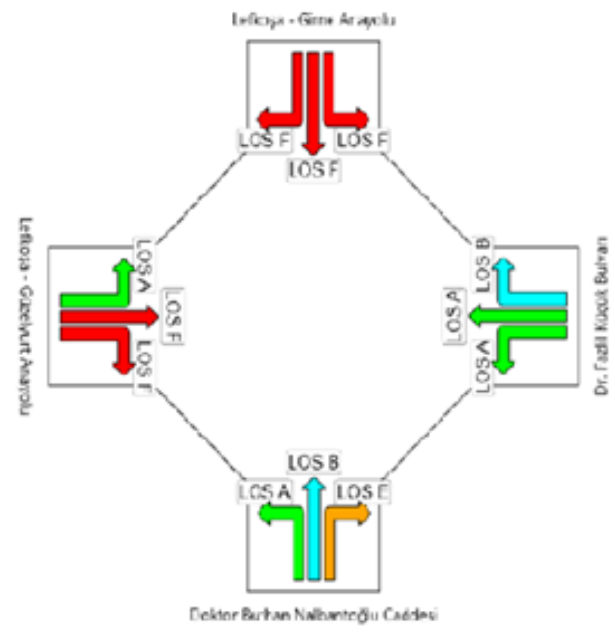

(a)

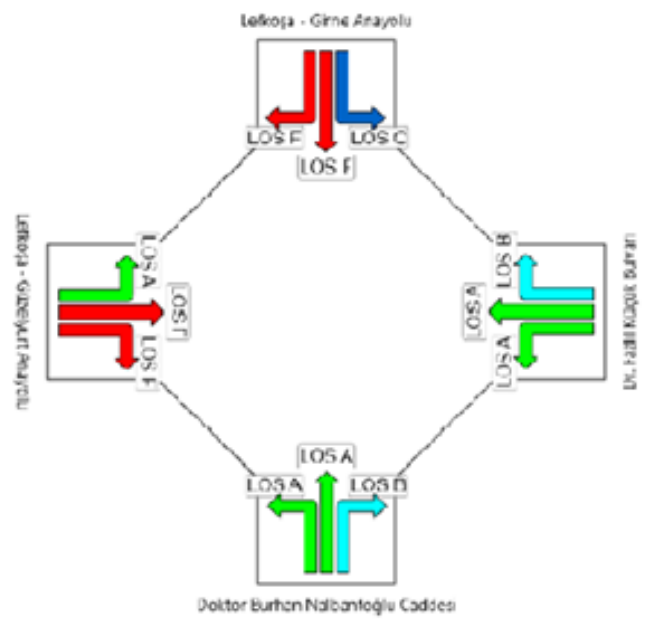

(b)

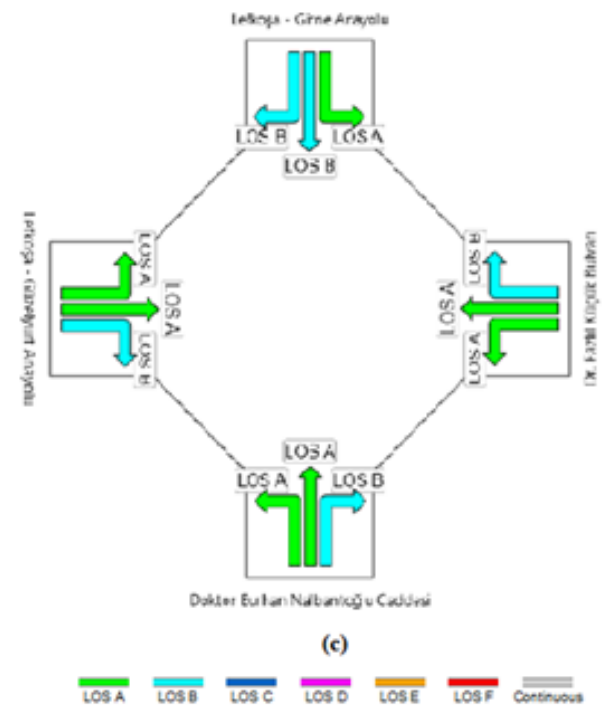

Figure 5. Details of LOS for Gönyeli Roundabout; (a) current study, (b) first possible solution applied and (c) second possible solution applied. 


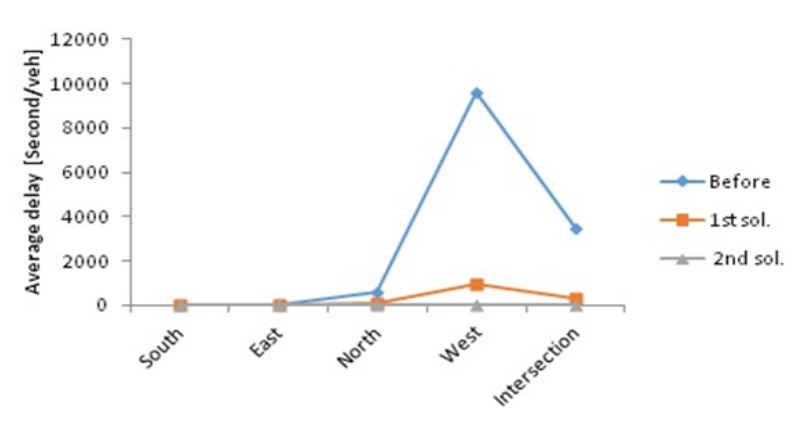

Figure 6. Average delay related to LOS for Gönyeli intersection. according to color code based on speed efficiency light blue color and dark blue color that the speed efficiency ratio between $(2.1-51.8)$ and $(43.5-45.1)$, respectively. In addition, the relationship between travel speed, travel time and all phases in all cases shows in Figure 8. It is significant to observe that the travel speed for the second case is increased compared to the current case and first case. In addition, travel time for the second case is reduced sharply compared to other cases. Moreover, averaged travel speed and travel time for second cases are nearly the same, which about $46 \mathrm{~km} / \mathrm{h}$ and $25 \mathrm{veh}-\mathrm{h} / \mathrm{h}$ respectively.

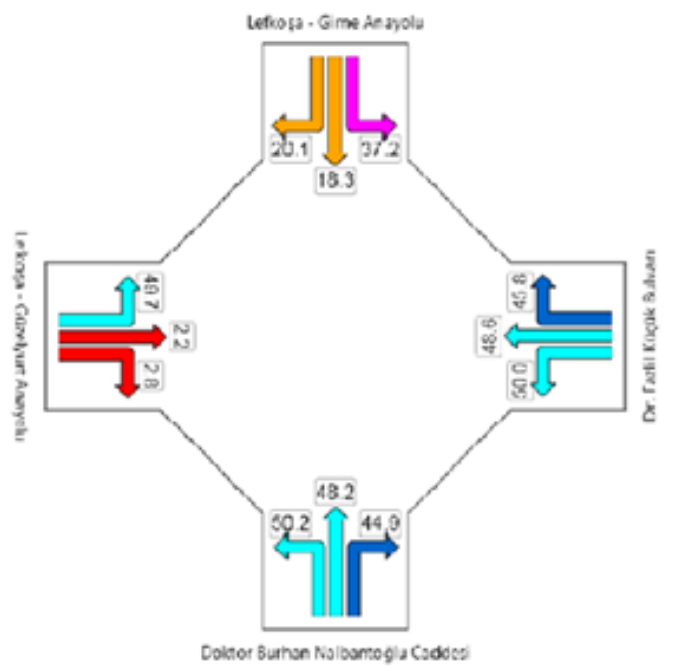

(b)

(a)

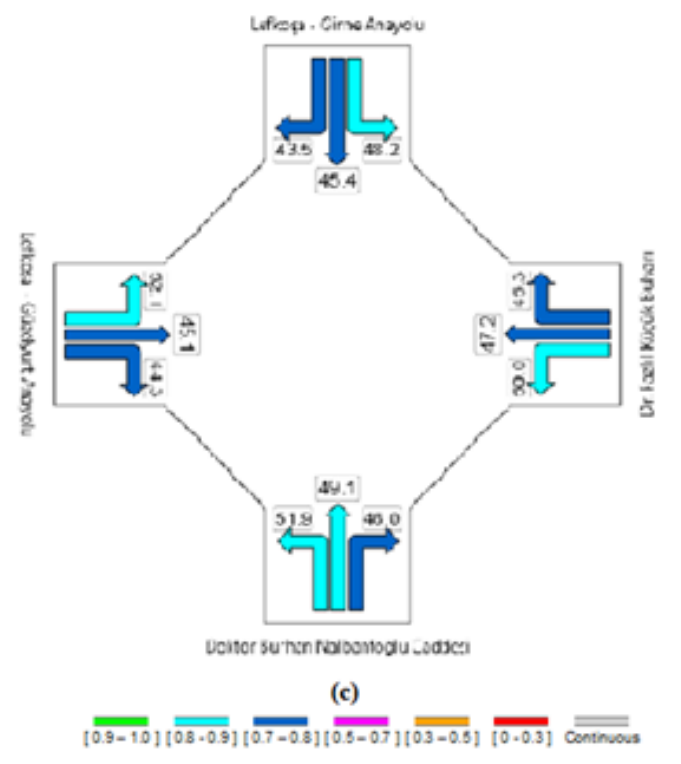

Figure 7. Details of travel speed for Gönyeli Roundabout; (a) current study, (b) first possible solution applied and (c) second possible solution applied. 


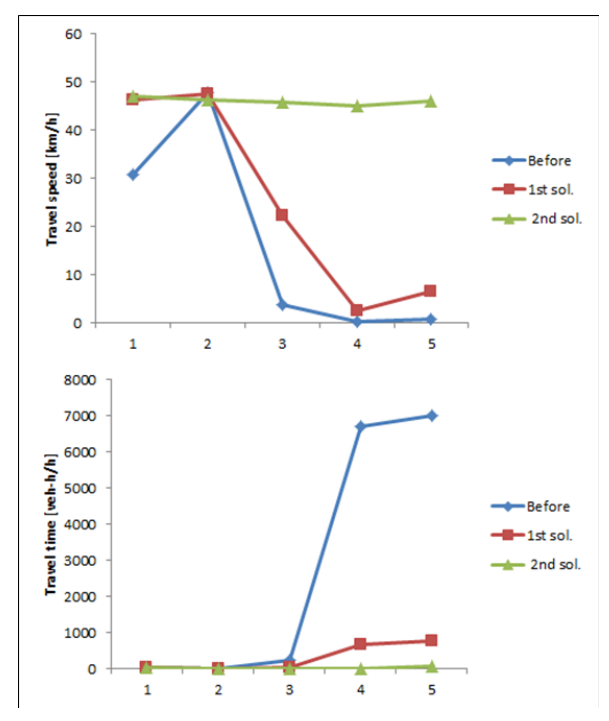

Figure 8. Travel speed, Travel time vs, phases for a Gönyeli intersection.

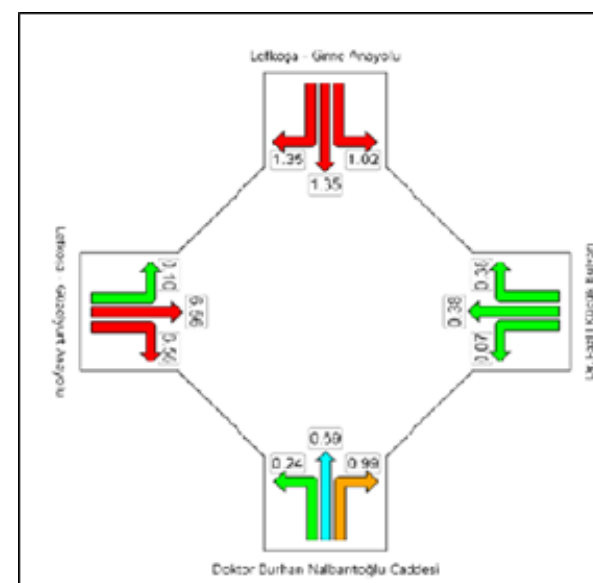

(a)

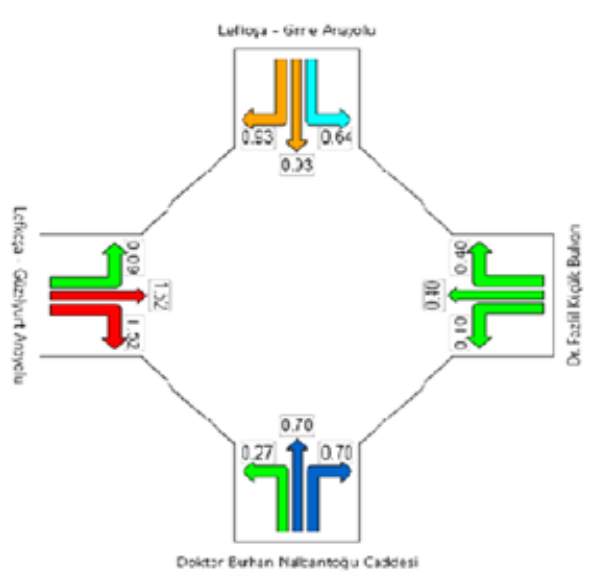

(b)

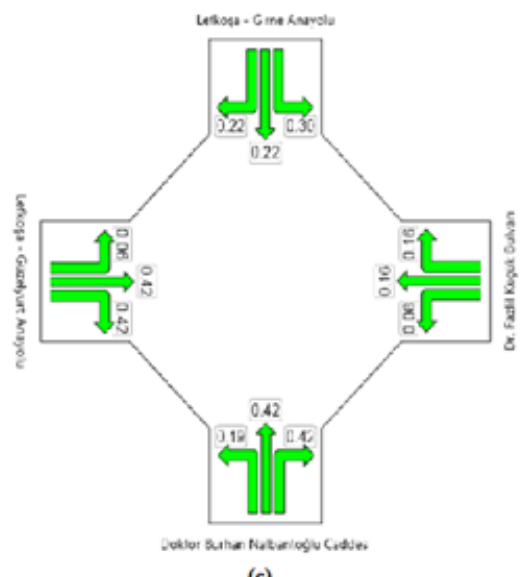

(c)

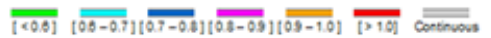

Figure 9. Details of degree of saturation for Gönyeli Roundabout; (a) current study, (b) first Possible solution applied and (c) second possible solution applied. 
A result for the degree of saturation is clarified in Figure 9. According to color code based on a degree of saturation, each degree has a specific color. For an instant, green color refers to less than 0.6 degrees of saturation, it was observed that all phases in the second case have green color means that degree of saturation approach $(<0.6)$, whilst in the first case, the phases have five color which depends on the direction. A relation between degrees of saturation and phases is illustrated in Figure 10. It is observed that the degree of saturation for Gönyeli intersection is $0.42 \mathrm{v} / \mathrm{c}$.

\subsubsection{Göçmenköy Roundabout}

Results illustrated that Göçmenköy intersection LOS in the current case is (F). After applying the possible solu-

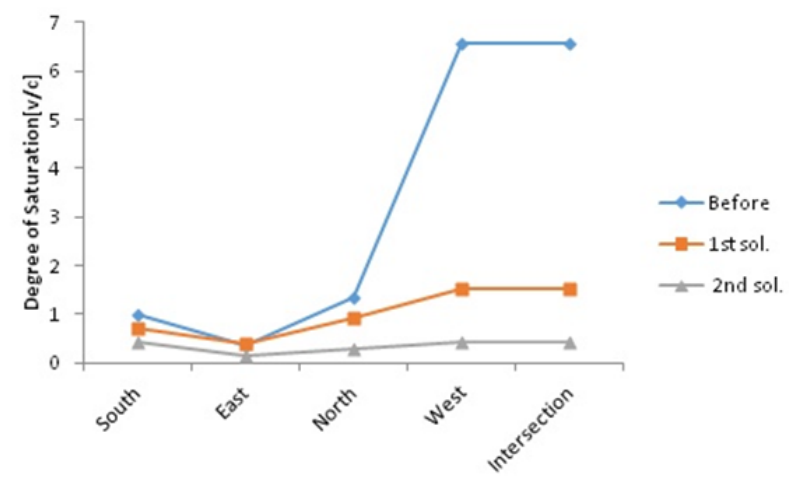

Figure 10. A degree of Saturation vs, phases for a Gönyeli intersection. tion, Göçmenköy intersection LOS in the first case (first case: applying the first solution) is (D) as shown in Figure 11(a),(b).

Resulting for the delay is indicated in Figure 4-9, which shows that all phases in the first case have four colors (red, light blue, dark blue and green), green refers to LOS A and light blue refers to LOS B, dark blue refers to LOS C and red refers to LOS F. It is observed that Dr. FazliKüçükBulvan (right of roundabout) right and through LOS are F. Also, Sanayi Cd right LOS is $\mathrm{F}$ as shown in Figure 11. Moreover, it is noticed that Dr. FazliKüçükBulvan (left of the roundabout) and Şht. Mustafa Mehmet LOS have two colors (green and blue). The relation between average delay and phases is illustrated in Figure 12. It is found that the average delay in Göçmenköy intersection is about $51.1 \mathrm{~second} / \mathrm{veh}$.

Indicated results for travel speed is in Figure 13, it was noted that all phases have a light blue, dark blue, red and purple colors. In addition, the relationship between travel speed, travel time and all phases in all cases shows in Figure 14. It is significant to observe that the travel speed for the first case is increased compared to the current case. Moreover, averaged travel speed and travel time for Göçmenköy intersection (first case) are about $25 \mathrm{~km} / \mathrm{h}$ and $124 \mathrm{veh}-\mathrm{h} / \mathrm{h}$, respectively.

A result for the degree of saturation is shown in Figure 15. Green color refers to less than 0.6 degrees of saturation
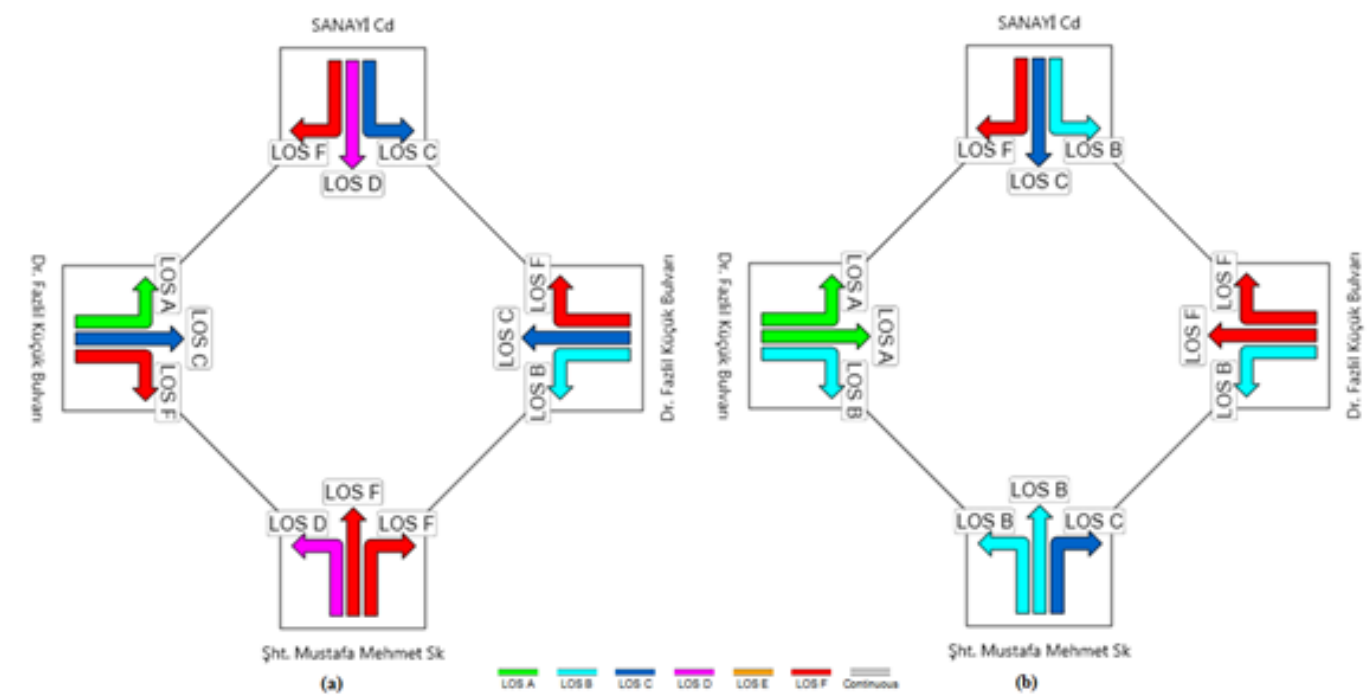

Figure 11. Details of LOS for Göçmenköy Roundabout; (a) current study, and (b) first possible solution applied. 
and blue color refers to the degree of saturation is between 0.6 and 0.7 degree, it was observed that Şht. Mustafa Mehmet Sk and Dr. FazliKüçükBulvan (lift) street have two colors, whilst in other phases have various colors, which depends on the directions as shown in Figure 15. A relation between degrees of saturation and phases is illustrated in Figure 16. It is observed that the degree of saturation for Göçmenköy intersection is $1.03 \mathrm{v} / \mathrm{c}$.

\subsubsection{Yenikent Roundabout}

Results illustrated that Yenikent intersection LOS in the current case is (F). After applying the solution, Yenikent intersection LOS is (C) as shown in Figure 17(b).

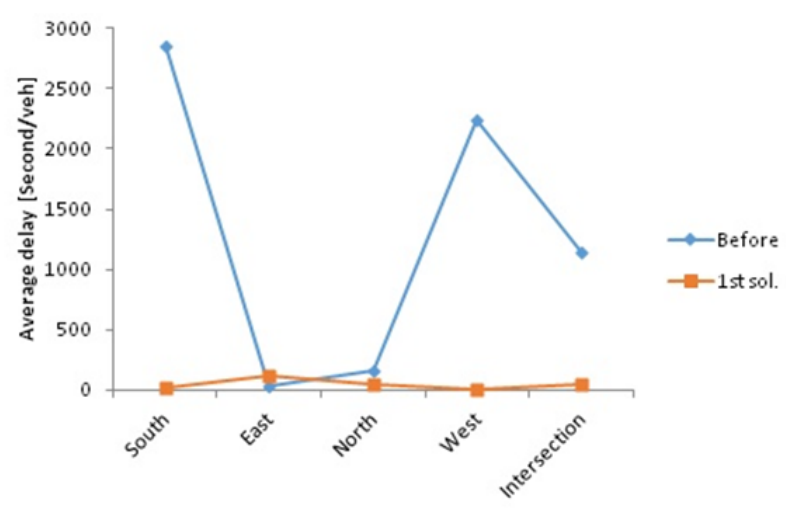

Figure 12. Average delay related to LOS for Göçmenköy intersection.
Resulting in the delay is indicated in Figure 17, which shows that all phases in the first case have four colors. The relation between average delay and phases is illustrated in Figure 18. It is found that the average delay in Yenikent intersection is about 33 second/veh.
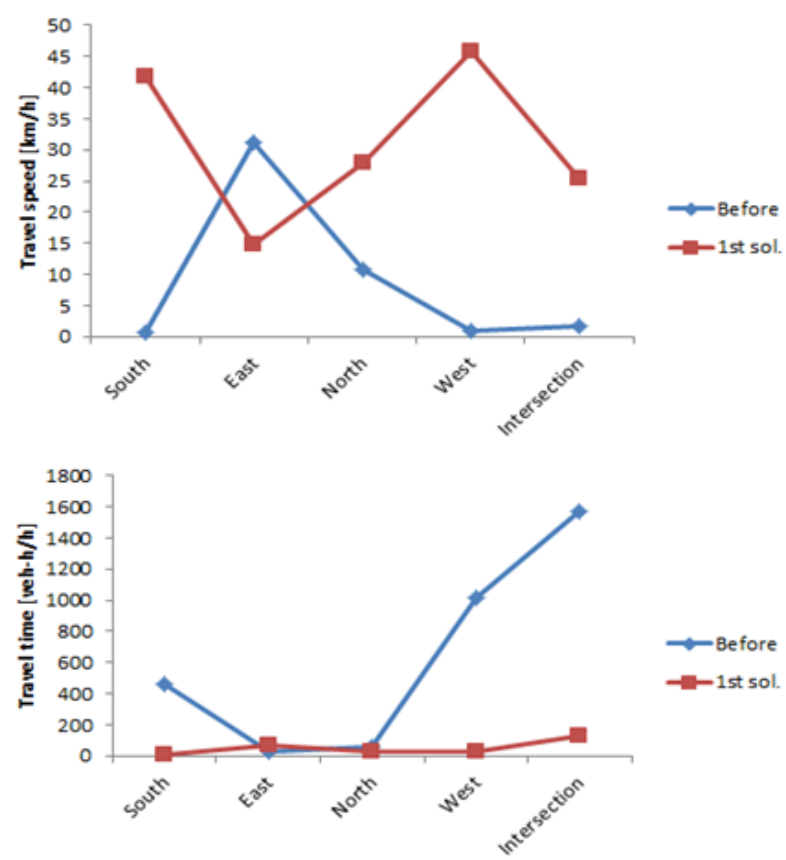

Figure 14. Travel speed, travel time vs, phases for Göçmenköy intersection.

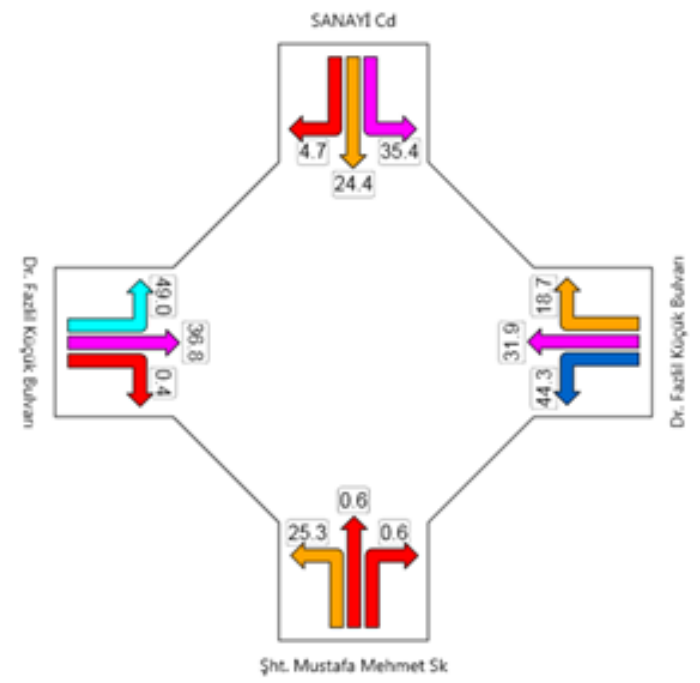

(a)

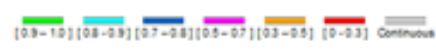

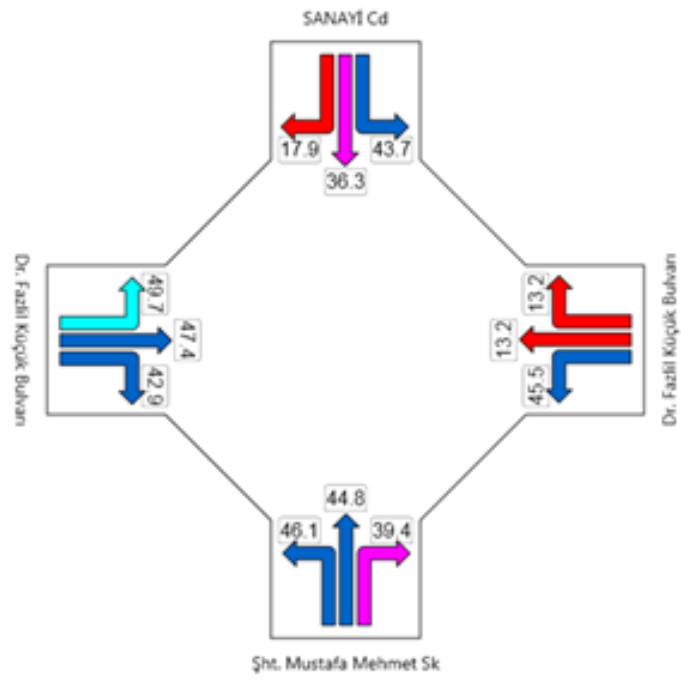

(b)

Figure 13. Details of travel speed for Göçmenköy Roundabout; (a) current study, and (b) first possible solution applied. 


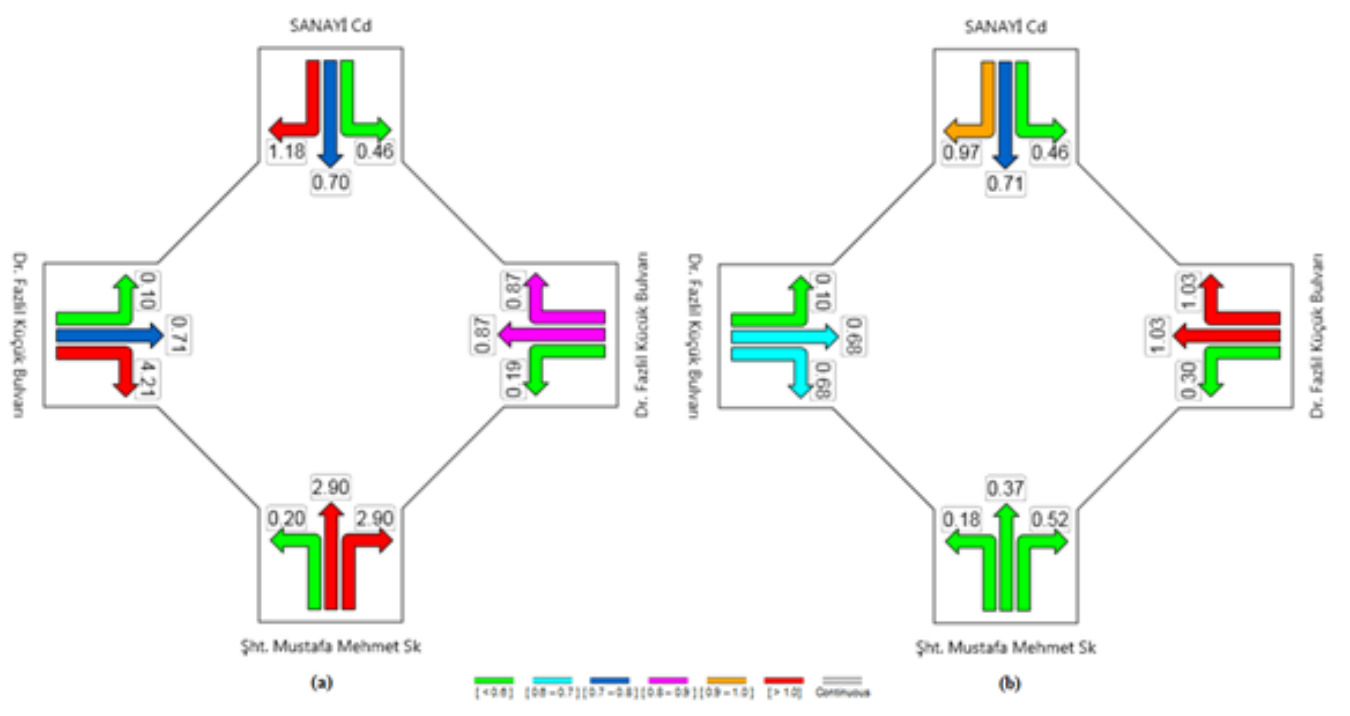

Figure 15. Details of degree of saturation for Göçmenköy Roundabout; (a) current study and (b) first possible solution applied.

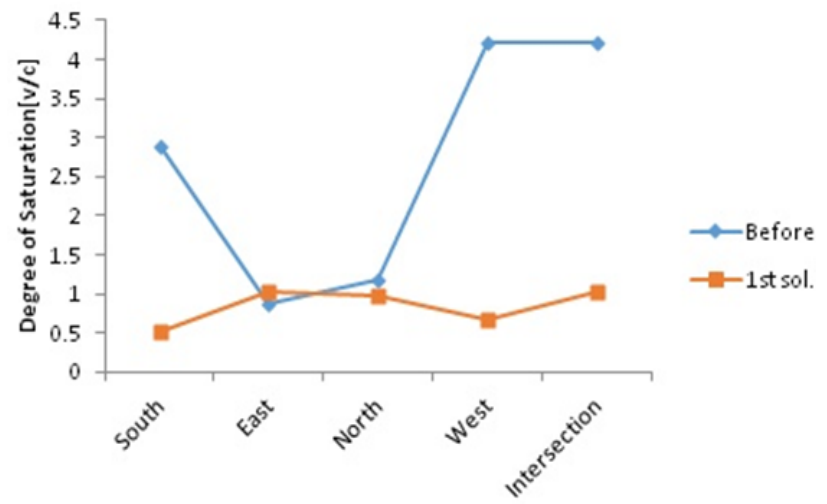

Figure 16. A degree of Saturation vs, phases for Göçmenköy intersection.

Results for travel speed are indicated in Figure 19, it was noted that dark blue is most color appeared in all phases. Furthermore, the relationship between travel speed, travel time and all phases in all cases shows in Figure 20. It is significant to observe that the travel speed for the first case is increased compared to the current case. Moreover, averaged travel speed and travel time for Yenikent intersection (first case) is about $31.9 \mathrm{~km} / \mathrm{h}$ and 412 veh-h/h, respectively.

The saturation degree results for all phases in Yenikent are shown in Figure 21. It is observed that Yenikent and Gönyeli streets have a green color, whilst Lefkoşa - GüzelyurtAnayolu and Güzelyurt - LefkoşaAnayolu purple and light brown colors, respectively. A relation between degrees of saturation and phases is illustrated in Figure 22. It is observed that the degree of saturation for Yenikent intersection is $0.97 \mathrm{v} / \mathrm{c}$.

\subsection{Environmental Effect}

The input to the SIDRA software includes the road geometry, traffic counts, and turning movements. The SIDRA software analyzes the data and the output provides measures of effectiveness from which the performance of the roadway can be determined.

The results obtained for each roundabout are then averaged and the overall results are given in Figures 23-25. 


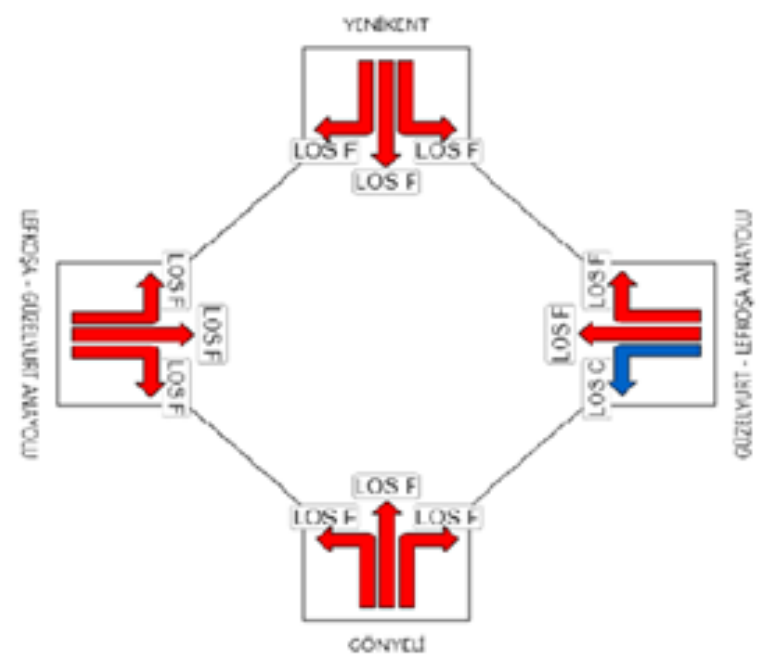

(a)

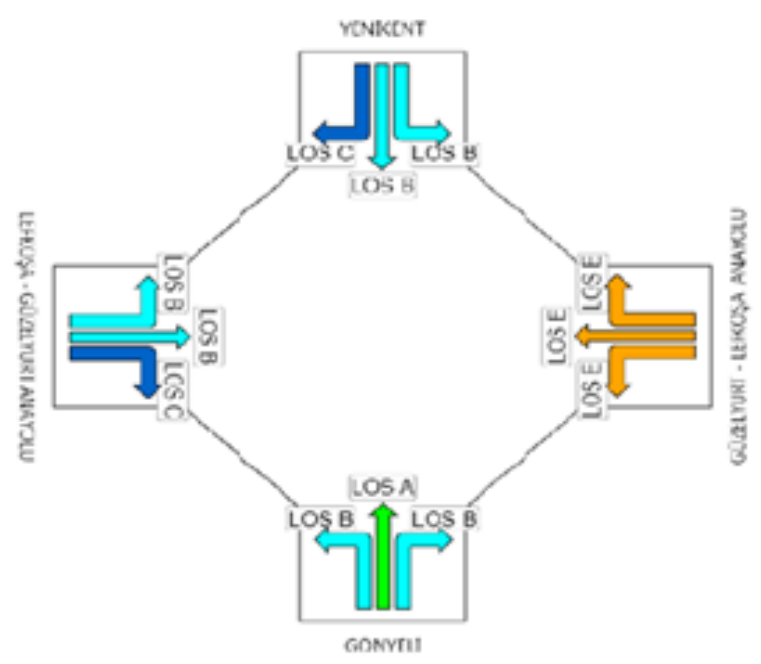

(b)

Figure 17. Details of LOS forYenikent Roundabout; (a) current study and (b) possible solution applied.

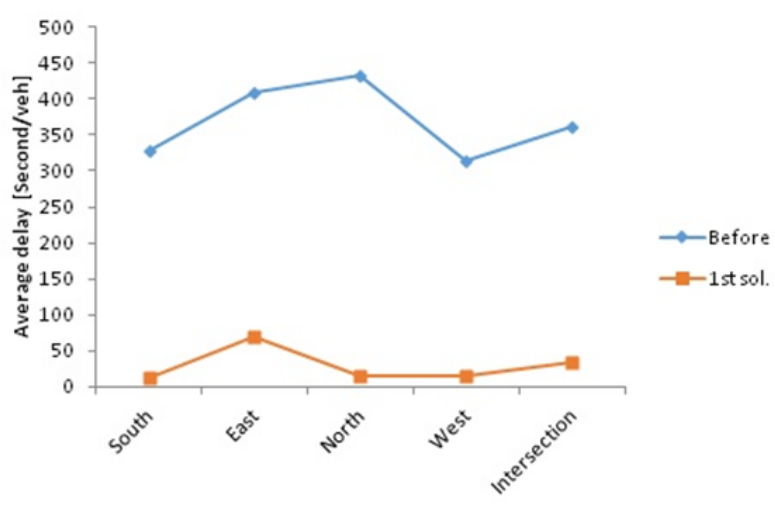

Figure 18. Average delay related to LOS for Yenikent intersection.

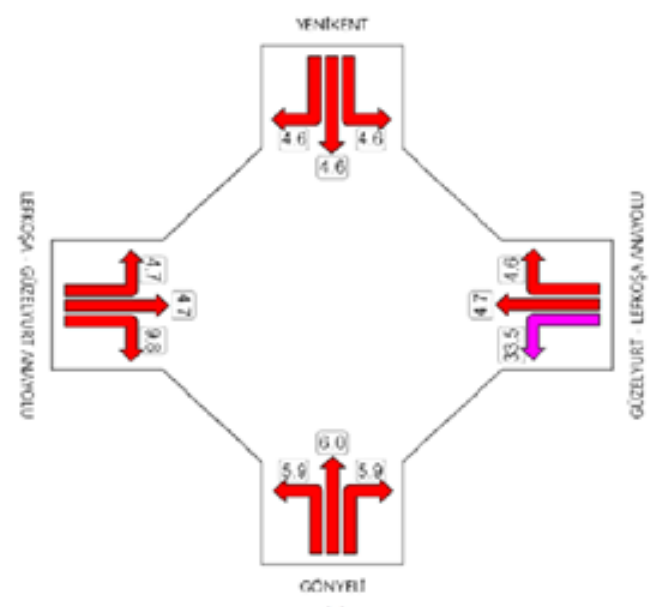

(a)

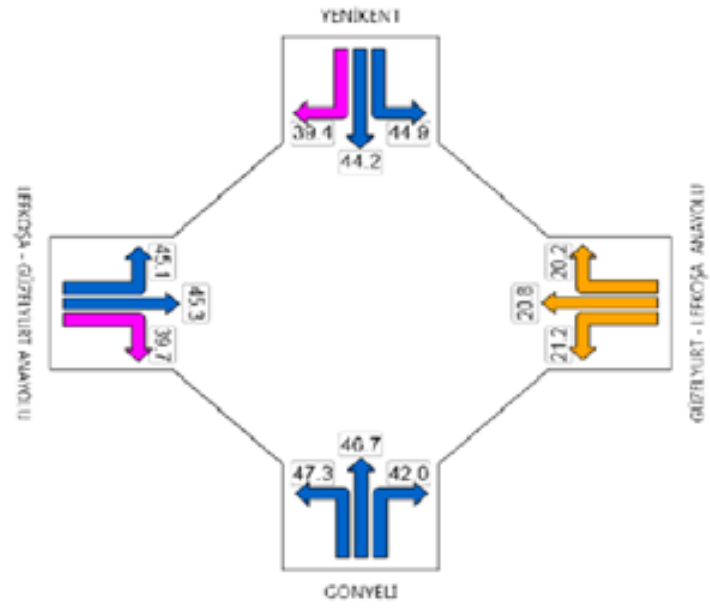

(b)

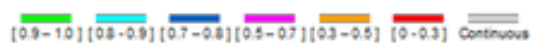

Figure 19. Details of travel speed for Yenikent Roundabout; (a) current study and (b) Possible solution applied. 


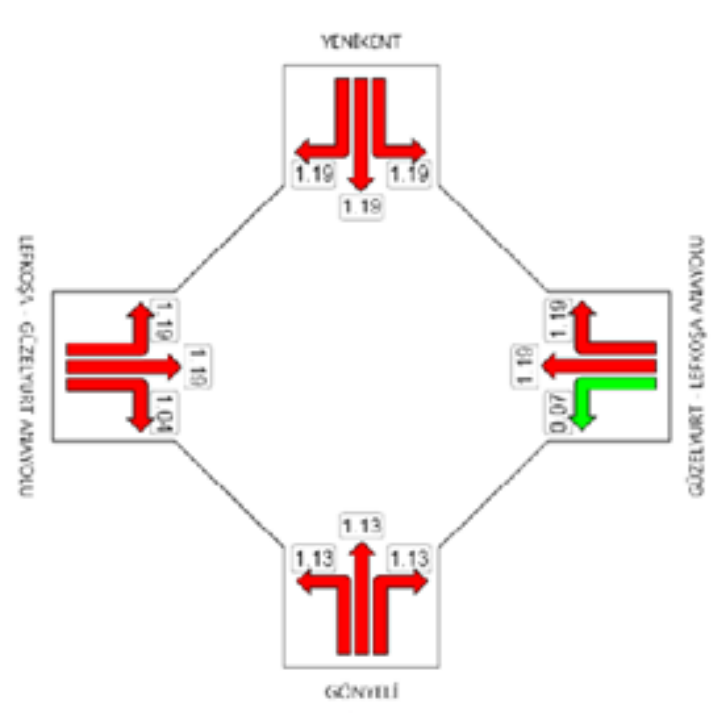

(a)

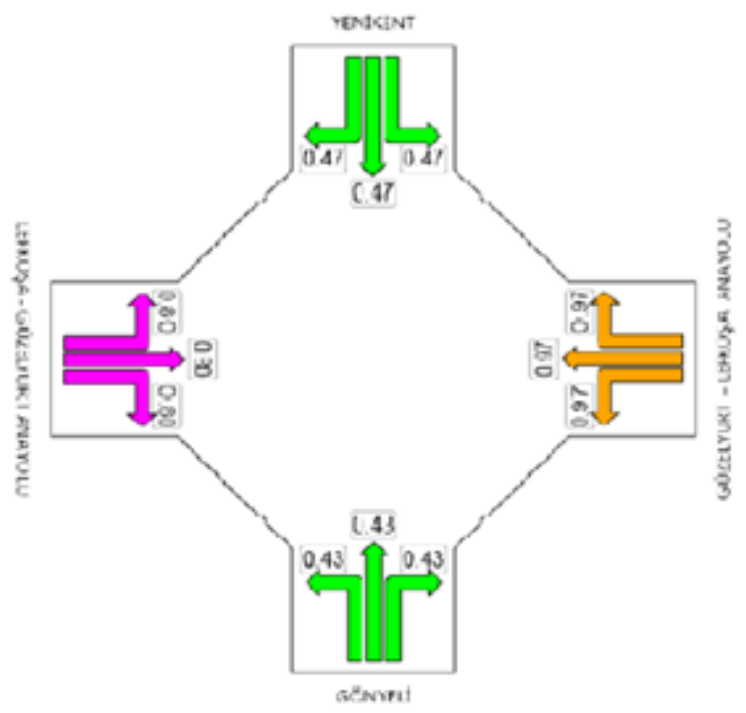

(b)

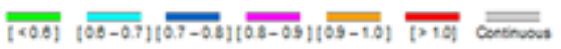

Figure 21. Details of the degree of saturation for Yenikent intersection; (a) current study and (b) Possible solution applied.
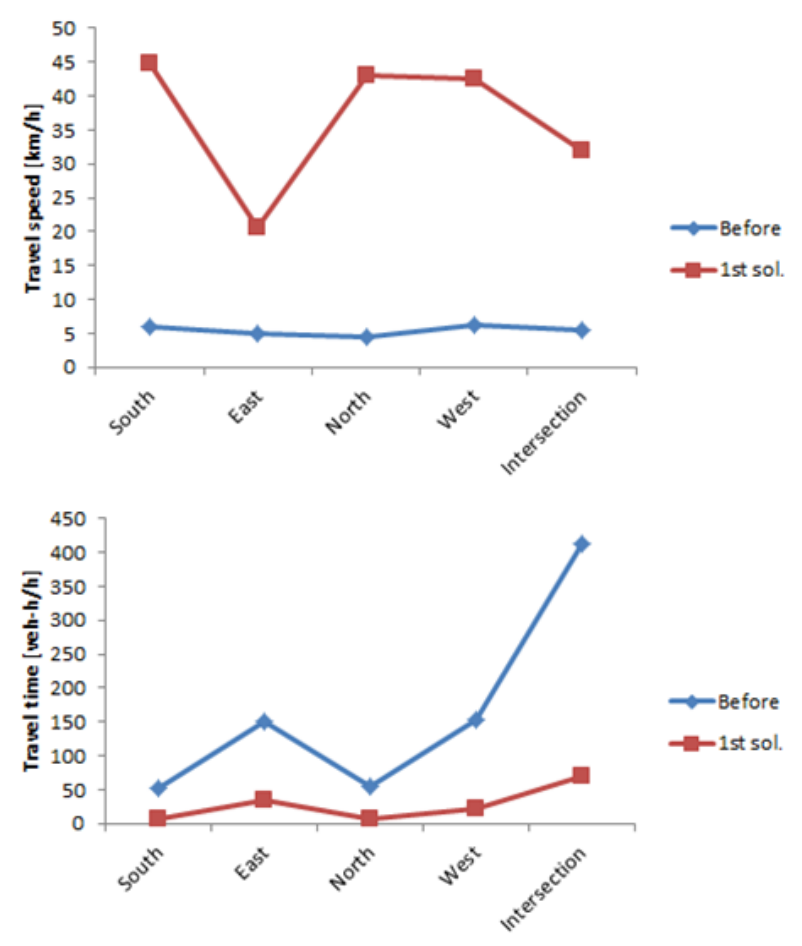

Figure 20. Travel speed, Travel time vs, and phases for Yenikent intersection.

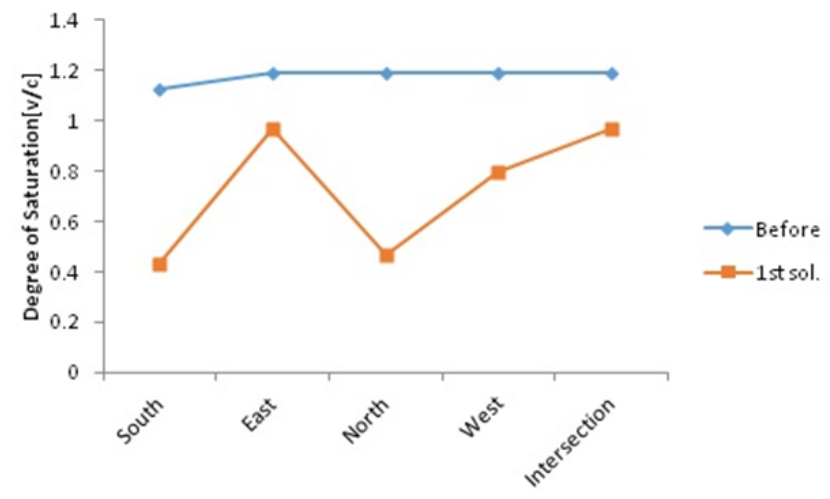

Figure 22. A degree of Saturation vs, phases for Yenikent intersection. 
It can be seen that percentage of $\mathrm{CO}_{2}$ emissions $(\mathrm{kg} / \mathrm{h})$ for Gönyeli intersection location studied is reduced sharply i.e. $84 \%$ for the first case and $81 \%$ for second case reduction after applying the possible solutions as shown in Figure 23(a). It is found that the percentage of $\mathrm{CO}_{2}$ emissions reduction from the first case is higher compared to the second case. Based on the simulation results, it is observed that average $\mathrm{CO}_{2}$ emissions were reduced by $81 \%$ for Göçmenköy and 65\% for Yenikent as shown in Figure 24(a) and 25(a).

Furthermore, the average $\mathrm{HC}$ emissions $(\mathrm{kg} / \mathrm{h})$ for the intersection locations studied are $72 \%, 86 \%$ and $43 \%$ less for Gönyeli intersection, Göçmenköy intersection and Yenikentintersection, respectively (Figures 23-25(b)).

Additionally, as shown in Figure 23(c), the average percentage of $\mathrm{CO}$ emissions reduction $(\mathrm{kg} / \mathrm{h})$ for the intersection locations studied is about $61 \%$ for the first case and $75 \%$ for the second case. Moreover, the average percentage of $\mathrm{CO}$ emissions reduction for Göçmenköyroundabout and Yenikent roundabout is about $47 \%$ for both intersections as shown in Figures 24(c) and 25(c). It can be concluded that the decrease in $\mathrm{CO}$ emissions after applying the proposed solutions a roundabout was statistically

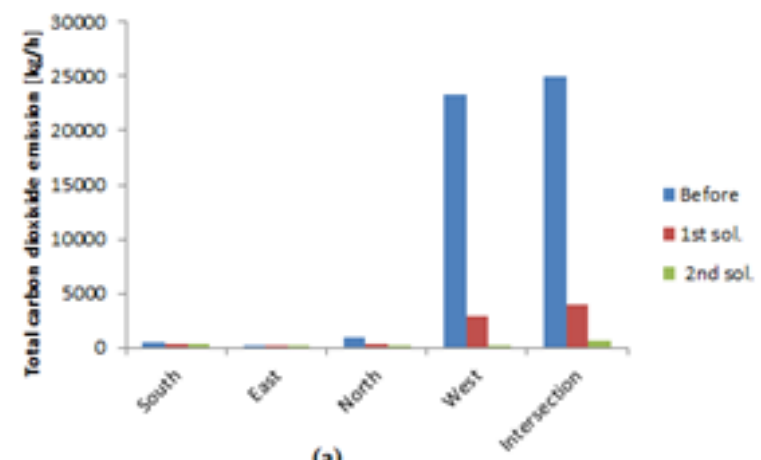

(a)

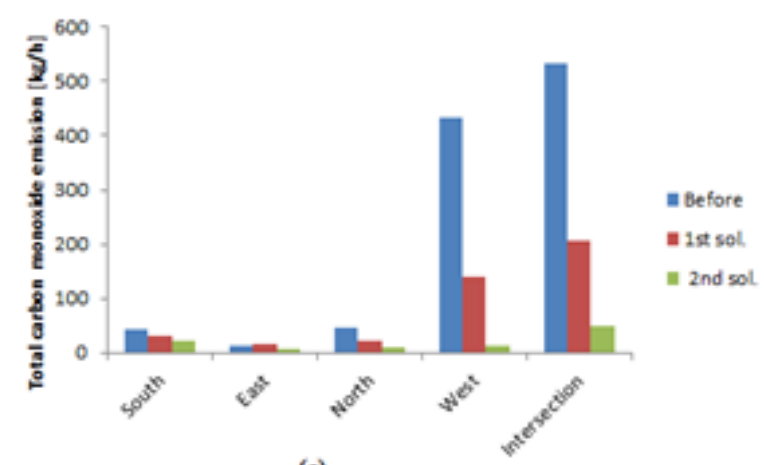

(c) different from the emissions that occurred in the current case for all intersections.

Moreover, the average NOX emissions $(\mathrm{kg} / \mathrm{h})$ for all the intersections was reduced suddenly i.e. from 58.441 $\mathrm{kg} / \mathrm{h}$ to $1.173 \mathrm{~kg} / \mathrm{h}$ for Gönyeli intersection, from 13.683 $\mathrm{kg} / \mathrm{h}$ to $2.067 \mathrm{~kg} / \mathrm{h}$ Göçmenköy intersection and 4.442 $\mathrm{kg} / \mathrm{h}$ to $1.274 \mathrm{~kg} / \mathrm{h}$ for Yenikent intersection as shown in Figures 23-25(d).

Overall, statistical tests showed that the decrease in the measures of effectiveness in all intersections after applying the possible solutions was statistically different from the emissions that occurred in the current cases i.e. The possible solutions can be helped to reduce the emissions in North Nicosia.

\subsection{Fuel Consumption and Cost Parameters}

SIDRA software was used for estimating the fuel consumption and cost parameters including total vehicles operating and time cost in this study. The operating cost estimates include:

1. The direct vehicle operating cost (the resource cost of fuel and additional running costs including a tire, oil,
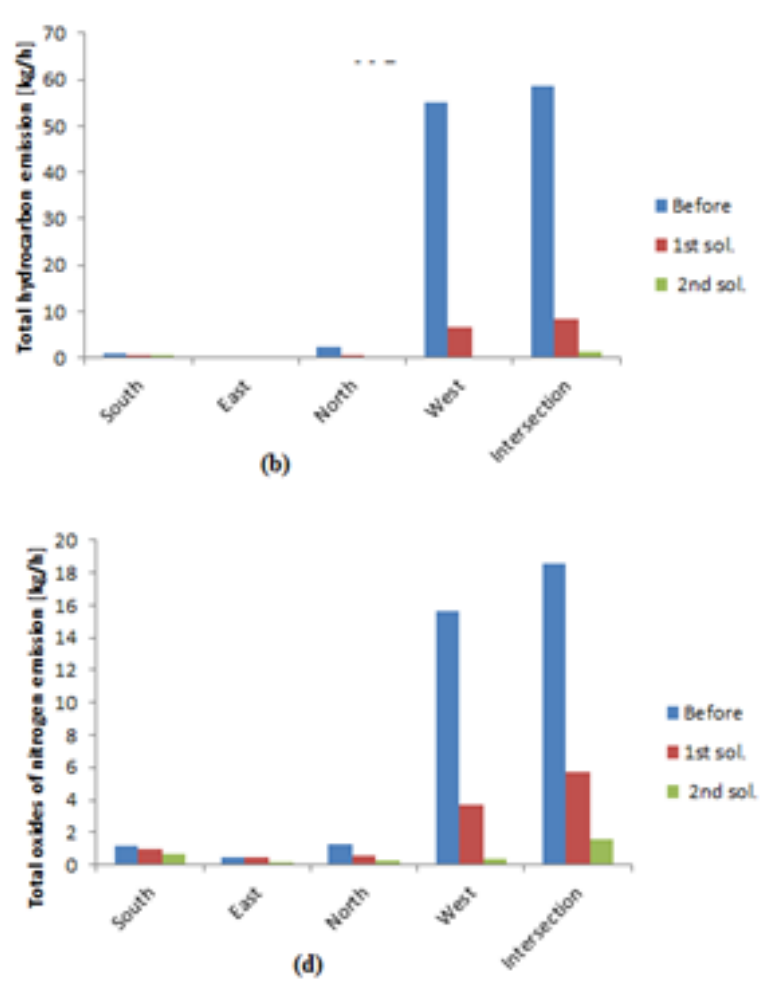

Figure 23. MOEs for Gönyeli roundabout: (a) $\mathrm{CO}_{2}$, (b) $\mathrm{HC},(\mathrm{c}) \mathrm{CO}$ and (d) $\mathrm{NO}_{\mathrm{x}}$. 

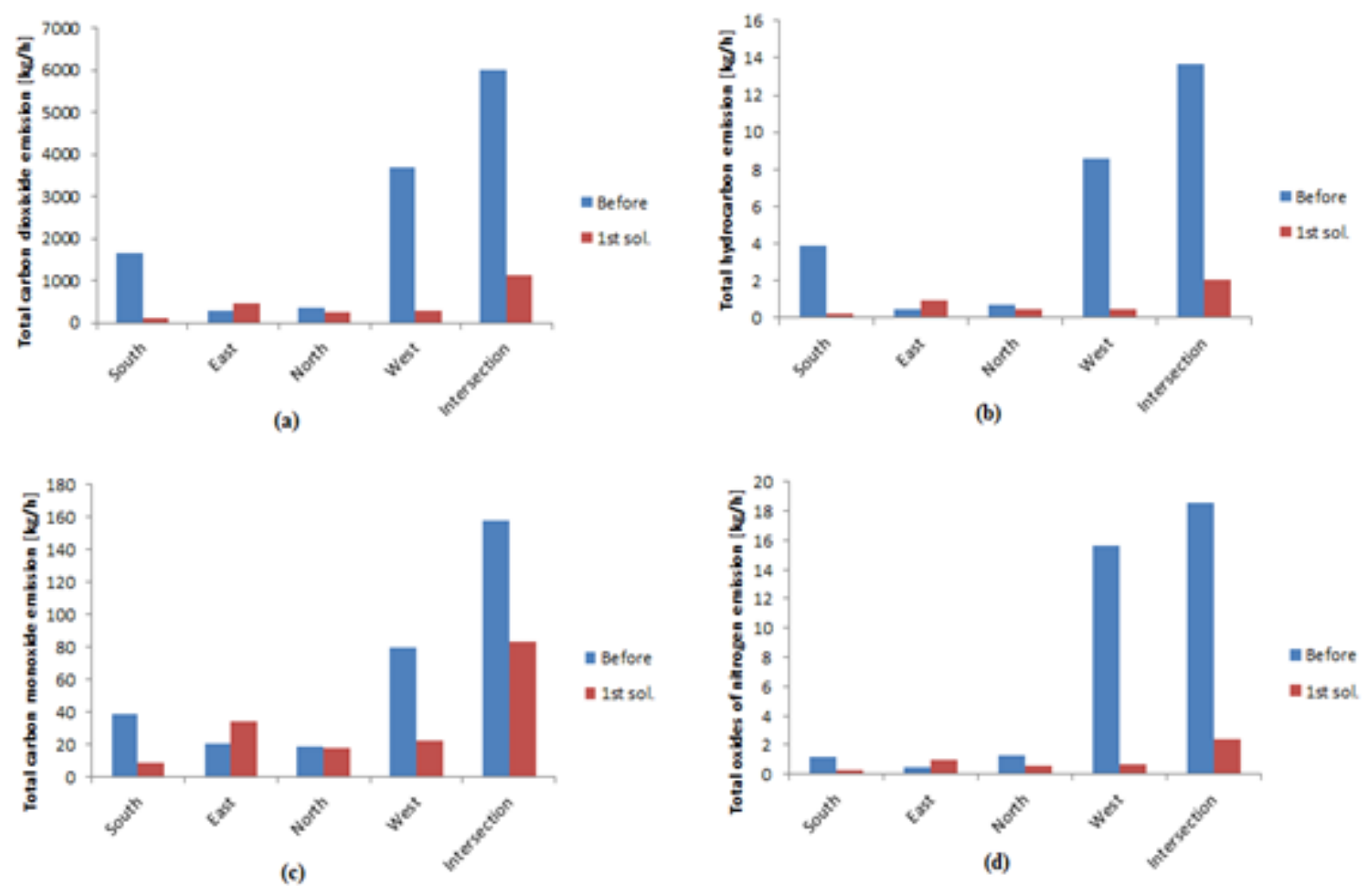

Figure 24. MOEs for Göçmenköy roundabout: (a) $\mathrm{CO}_{2}$, (b) $\mathrm{HC}$, (c) $\mathrm{CO}$ and (d) $\mathrm{NO}_{\mathrm{x}}$.
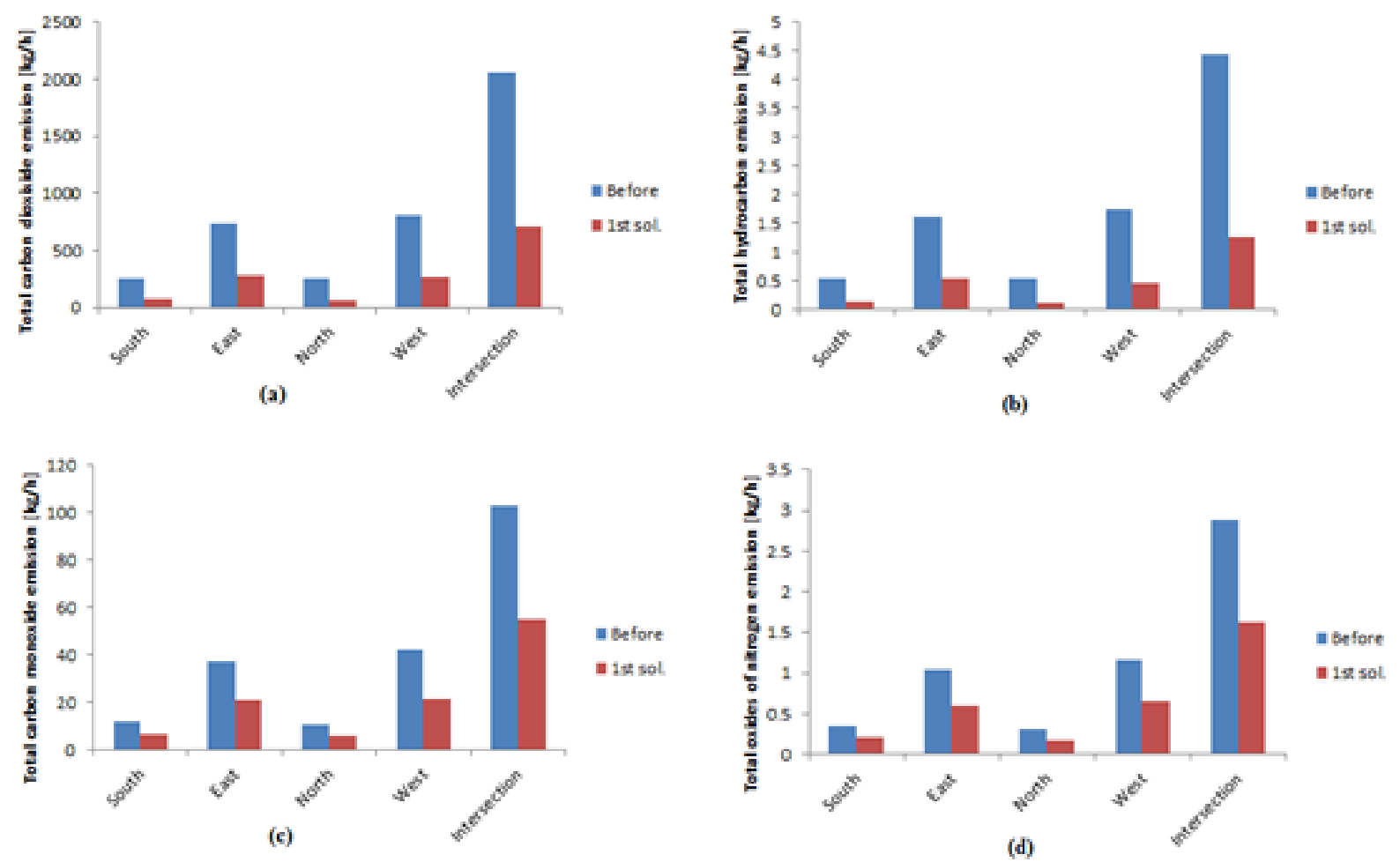

Figure 25. MOEs for Yenikent roundabout: (a) $\mathrm{CO}_{2}$, (b) $\mathrm{HC}$, (c) $\mathrm{CO}$ and (d) $\mathrm{NO}_{\mathrm{x}}$. 
repair, and maintenance as a factor of the cost of fuel), and

2. The time cost to driver and passengers.

Fuel consumptions and cost parameters of three intersections for all cases (current case, the first case, after applying the first possible solution, and the second case, after applying second possible solution) are tabulated in Table 3 and 4, respectively.

It is noticed that the fuel consumptions have reduced rapidly with an average percentage of about $75 \%$ for all intersections as shown in Table 3. In addition, the average percentage of total vehicles operating and time cost for Gönyeli, Göçmenköy, and Yenikent intersections were around $94 \%, 68 \%$, and $81 \%$, respectively as shown in Table 4. Overall, it can be concluded that the possible solutions can be used to solve the traffic congestion in North Nicosia.

\section{Conclusions}

Traffic congestion has significant social, economic, and environmental costs associated with it. The efficiency of intersectionscontributessignificantlytowardstheefficiency of whole urban road networks as they are the main bottlenecks in the system. Computer simulation is a vital means for the examination of expressways and urban lanes and streets.

The objective of this study is to calculate and analyses the travel time, delay time, degree of saturation, and level

Table 3. Fuel consumptions in $\mathrm{L} / \mathrm{h}$ for all intersection

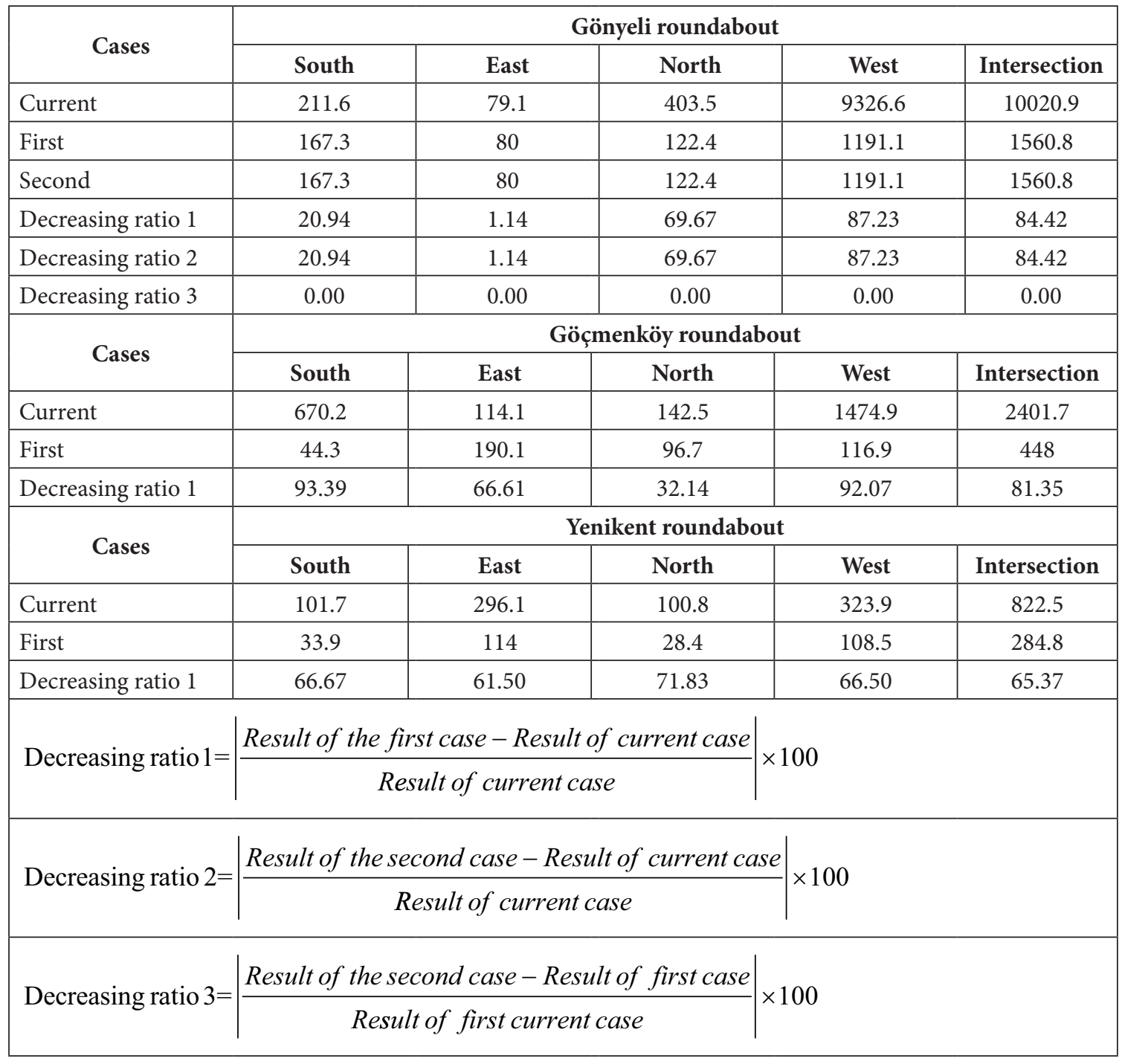


Table 4. Total vehicles operating and time cost in $\$ / \mathrm{h}$

\begin{tabular}{|c|c|c|c|c|c|}
\hline \multirow{2}{*}{ Cases } & \multicolumn{5}{|c|}{ Gönyeli roundabout } \\
\hline & South & East & North & West & Intersection \\
\hline Current & 1350 & 407.2 & 5676.5 & 169447.8 & 176881.4 \\
\hline First & 876.5 & 409 & 959.6 & 17197.3 & 19442.4 \\
\hline Second & 654.3 & 209.5 & 273.4 & 390 & 1527.1 \\
\hline Decreasing ratio 1 & 35.07 & 0.44 & 83.10 & 89.85 & 89.01 \\
\hline Decreasing ratio 2 & 51.53 & 48.55 & 95.18 & 99.77 & 99.14 \\
\hline Decreasing ratio 3 & 25.35 & 48.78 & 71.51 & 97.73 & 92.15 \\
\hline \multirow{2}{*}{ Cases } & \multicolumn{5}{|c|}{ Göçmenköy roundabout } \\
\hline & South & East & North & West & Intersection \\
\hline Current & 12976.4 & 944.7 & 1856.3 & 28641.8 & 44419.2 \\
\hline First & 319.3 & 2073.9 & 840.6 & 815.7 & 4049.4 \\
\hline Decreasing ratio 1 & 97.54 & 119.53 & 54.72 & 97.15 & 90.88 \\
\hline \multirow{2}{*}{ Cases } & \multicolumn{5}{|c|}{ Yenikent roundabout } \\
\hline & South & East & North & West & Intersection \\
\hline Current & 1517.8 & 4450 & 1589.1 & 4747.1 & 12304.1 \\
\hline First & 237.9 & 1106.9 & 202 & 774.9 & 2321.7 \\
\hline Decreasing ratio 1 & 84.33 & 75.13 & 87.29 & 83.68 & 81.13 \\
\hline \multirow{2}{*}{ Decreasing ratio $1=$} & \multicolumn{3}{|c|}{ Result of the first case-Result of current case } & \multirow{2}{*}{\multicolumn{2}{|c|}{100}} \\
\hline & \multicolumn{3}{|c|}{ Result of current case } & & \\
\hline \multirow{2}{*}{ Decreasing ratio $2=$} & \multicolumn{3}{|c|}{ Result of the second case-Result of current case } & \multirow{2}{*}{$\times 100$} & \\
\hline & \multicolumn{3}{|c|}{ Result of current case } & & \\
\hline \multirow{2}{*}{ Decreasing ratio $3=$} & \multicolumn{3}{|c|}{ Result of the second case-Result of first case } & \multirow{2}{*}{\multicolumn{2}{|c|}{100}} \\
\hline & Resul & st curre & & & \\
\hline
\end{tabular}

of service and travel speed in three intersections in North Nicosia using SIDRA software.

Conclusions based on the investigation done in this study are below:

- Based on SPSS results, it is found that the most congested intersections in the selected area are Göçmenköy roundabout, Gönyeli roundabout, and Yenikent roundabout,

- The statistical analysis of the MOEs helps determine if and how the stop-controlled intersections and the roundabout- controlled intersections differed in cutting down vehicular emissions. The analysis provides information to assess characteristics of the stop controls and the roundabout, and

- It is concluded that at the intersections studied the modern roundabouts significantly reduced the vehicular emissions of the intersections studied by making the traffic flow orderly.

\section{Acknowledgments}

The authors would like to thank the Faculty of Civil and Environmental Engineering especially the Civil Engineering Department at Near East University for their support and encouragement. 


\section{References}

1. Lin S, Zhou Z, Xi Y. Model-Based Traffic Congestion Control in Urban Road Networks, Transportation Research Record: Journal of the Transportation Research Board. 2013; 2390(1):112-120. https://doi.org/10.3141/2390-12.

2. Shamsher $\mathrm{R}$, Abdullah MN. Traffic Congestion in Bangladesh- Causes and Solutions: A study of Chittagong Metropolitan City, Asian Business Review. 2013; 2(1):13-18. https://doi.org/10.18034/abr.v2i1.309, https:// doi.org/10.18034/abr.v2i1.116

3. He F, Yan X, Liu Y, Ma L. A traffic congestion assessment method for urban road networks based on speed performance index, Procedia Engineering. 2016; 137:425-33. https://doi.org/10.1016/j.proeng.2016.01.277.

4. Chen X, Shan X, Ye J, Yi F, Wang Y. Evaluating the effects of traffic congestion and passenger load on feeder bus fuel and emissions compared with passenger car, Transportation Research Procedia. 2017; 25:616-26. https://doi. org/10.1016/j.trpro.2017.05.446.

5. Jain S, Jain SS, Jain G. Traffic congestion modelling based on origin and destination, Procedia Engineering. 2017; 187:442-50. https://doi.org/10.1016/j.proeng.2017.04.398.
6. Stepanchuk O, Bieliatynskyi A, Pylypenko O, Stepanchuk S. Surveying of traffic congestions on arterial roads of Kyiv City, Procedia Engineering. 2017; 187:14-21. https://doi. org/10.1016/j.proeng.2017.04.344.

7. Rao AM, Rao KR. Measuring urban traffic congestion, Review, International Journal for Traffic and Transport Engineering. 2012; 22(4):286-305.

8. Agyapong F, Ojo TK. Managing traffic congestion in the Accra Central Market, Ghana, Journal of Urban Management. 2018; 7(2):85-96. https://doi.org/10.1016/j. jum.2018.04.002.

9. Kiunsi RB. A review of traffic congestion in Dar es Salaam City from the physical planning perspective, Journal of Sustainable Development. 2013; 6(2):1-10. https://doi. org/10.5539/jsd.v6n2p94.

10. Jain K, Vazirani VV. Eisenberg-Gale markets: Algorithms and game-theoretic properties, Games and Economic Behavior. 2010; 70(1):84-106. https://doi.org/10.1016/j. geb.2008.11.011.

11. Zhang J, Yu Y, Lei Y. The Study on an Optimized Model of Traffic Congestion Problem Caused by Traffic Accidents. Chinese Control and Decision Conference (CCDC); 2016. p. 668-92. https://doi.org/10.1109/CCDC.2016.7531073. 